\title{
Gamma Attenuation Properties of Some Aluminum Alloys
}

\author{
S. Yildirim*, A.B. Tugrul, B. Buyuk and E. Demir \\ Istanbul Technical University, Energy Institute, Nuclear Researches Division, ITU Ayazaga Campus, \\ 34469, Sariyer, Istanbul, Turkey
}

\begin{abstract}
In the present work, several commonly used aluminum alloys were investigated for their protective properties against gamma radiation. The gamma transmission technique was used to study the gamma attenuation behavior of the alloys. Cs-137 (0.662 MeV) and Co-60 (1.25 MeV) gamma radioisotope sources, which have relatively medium and high gamma energy levels, were used as gamma sources. The linear and mass attenuation coefficients of the aluminum alloys were measured. The mass attenuation coefficients of the samples were compared with the theoretical values which were calculated using XCOM computer code. The difference between the experimental and theoretical values was below $5 \%$. In addition half-value layer (HVL) values for the studied aluminum alloys were calculated using the linear attenuation coefficients. The attenuation coefficients of the different aluminum alloys were compared. The biggest HVL was observed for 1050 alloy, for both gamma isotope sources, which means the smallest gamma attenuation capability among the studied alloys. It is concluded that the alloys were applicable for the gamma radiation shielding applications.
\end{abstract}

DOI: 10.12693/APhysPolA.129.813

PACS/topics: 25.20.Dc

\section{Introduction}

Aluminum is one of the light engineering metals, having a strength to weight ratio superior to steel. Pure aluminum is relatively soft, ductile, and corrosion resistant and has a high electrical conductivity. It is widely used for foil and conductor cables, but alloying with other elements is necessary to provide a higher strength needed for other applications. Aluminum alloys are used in engineering structures in a wide range of the industrial sectors. Most of the aluminum reaching the marketplace is alloyed and such alloys have extensive application areas [1].

By utilizing various combinations of its advantageous properties such as strength, lightness, corrosion resistance, recyclability and formability, aluminum is being employed in an ever-increasing number of applications. Aluminum is the most strong and resistant material for every season. It is 43 times more lasting than wood, 23 times more lasting than PVC. It does not need the extra protection against ultra violet light. In an alloy aluminum can be strong and durable as much as iron and steel. On the other hand aluminum is by $1 / 3$ lighter than these metals. The array of aluminum alloy products ranges from structural materials to thin packaging foils. Alloy systems are classified by a number system of ANSI. Aluminum alloys are also used in nuclear reactors for different purposes (e.g. it is used as the tank material for the TRIGA Mark Reactors). In this study, the behavior of aluminum alloys against gamma radiation was investigated. Several aluminum alloys were studied in the experiments.

\footnotetext{
* corresponding author; e-mail: selahattin06_yildirim@hotmail.com
}

\section{Experimental procedures 2.1. Materials}

In this study, six different aluminum alloys were used in experiments. The contents of the studied aluminum alloys is given in Table I [2].

TABLE I

The contents of studied aluminum alloys.

\begin{tabular}{c|c|c|c|c|c|c|c|c|c}
\hline \hline Alloys & $\mathrm{Fe}$ & $\mathrm{Si}$ & $\mathrm{Zn}$ & $\mathrm{Cr}$ & $\mathrm{Ti}$ & $\mathrm{Mg}$ & $\mathrm{Mn}$ & $\mathrm{Cu}$ & Others \\
\hline 1050 & 0.4 & 0.25 & 0.07 & - & 0.05 & 0.05 & 0.05 & 0.05 & - \\
3003 & 0.7 & 0.6 & 0.1 & - & - & - & $1.0-1.15$ & $0.05-0.2$ & 0.15 \\
5005 & 0.7 & 0.3 & 0.25 & 0.10 & - & $0.50-1.1$ & 0.2 & 0.2 & 0.15 \\
6063 & 0.35 & $0.20-0.6$ & 0.1 & 0.1 & 0.1 & $0.45-0.9$ & 0.10 & 0.1 & 0.15 \\
7072 & 0.7 & $\mathrm{Fe}+\mathrm{Si}$ & $0.8-1.3$ & - & 0.15 & - & 0.10 & 0.10 & 0.05 \\
8006 & $1.2-2.0$ & 0.40 & 0.10 & - & - & 0.10 & $0.3-1.0$ & 0.30 & 0.05
\end{tabular}

\subsection{Gamma sources}

In the experiments two main gamma radioisotopes were used as gamma source. One of them is Cs-137, which has a single gamma energy peak, and the other is Co-60, which has two energy peaks above the energy of $1 \mathrm{MeV}$. Properties of the gamma sources are given in Table II.

TABLE II

Properties of the studied gamma radioisotope sources [3].

\begin{tabular}{c|c|c|c}
\hline \hline Radioisotope & $\begin{array}{c}\text { Energy } \\
{[\mathrm{MeV}]}\end{array}$ & $\begin{array}{c}\text { Half-life } \\
{[\text { years] }}\end{array}$ & $\begin{array}{c}\text { Activity } \\
{[\mu \mathrm{Ci}]}\end{array}$ \\
\hline Cs-137 & 0.662 & 30.1 & 8.89 \\
Co-60 & $1.17 ; 1.33$ & 5.27 & 8.32
\end{tabular}

\subsection{Gamma transmission technique}

Gamma transmission technique is a radiogauging technique that is also a non-destructive method. It is used to examine the behavior of the materials against the radiation. The gamma source and the detector are placed 
on the opposite sides of the materials, on the same axis. Gamma radiation comes from the gamma source, penetrates the object and the detector detects the transmitted gamma rays [4-10]. The principle of the gamma transmission technique is shown in Fig. 1.
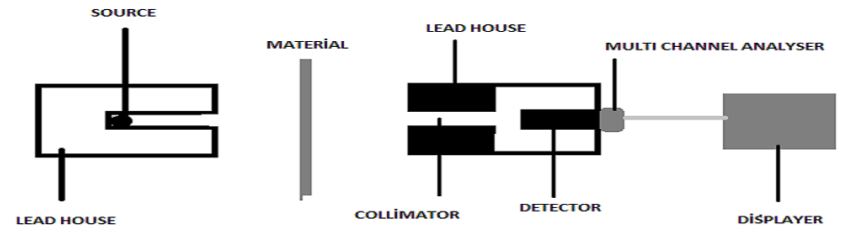

Fig. 1. Schematic view of the experimental set.

Lambert-Beer's equation is used for gamma transmission technique:

$$
I=I_{0} e^{-\mu x} \text {. }
$$

Here $I$ is beam intensity after transmission, $I_{0}$ is the incoming beam intensity, $\mu$ is the linear attenuation coefficient and, $x$ represents material thickness.

Mass attenuation coefficient can be found by the following formula:

$$
\mu_{m}=\frac{\mu}{\rho}
$$

where, $\mu_{m}$ is the mass attenuation coefficient of the material and $\rho$ is the density of the material.

In the experiments, gamma rays were detected by Canberra Model (802-2X2) NaI scintillation detector and digiBASE model PMT with integrated bias supply, preamplifier and digital multichannel analyser, which was supplied with MAESTRO-32 MCA Emulation software combined system. In experimental geometry lead blocks were used for radiation shielding and collimating of gamma rays, so scattering effect was minimized by using a $7 \mathrm{~mm}$ diameter harrow hole.

At first the background radiation and after that the initial gamma intensity without any material $\left(I_{0}\right)$ were measured. Gamma intensities $(I)$ were then measured for each material at different thicknesses. Net intensity counts were calculated by reducing the background. Each measurement was repeated minimum three times using the accumulation time of $300 \mathrm{~s}$. Relative intensities $\left(I / I_{0}\right)$ were calculated at different thicknesses. After that, the graphs which include relative intensity as a function of material thickness were drawn. The linear attenuation coefficients $(\mu)$ were calculated from the graphs by using Origin 8 computer program.

\section{Results and discussion}

The behavior of the aluminum alloys against the gamma radiation sources was studied experimentally. The experimental studies consist of two steps. In the first step, the transmission of gamma rays was measured with Cs-137 gamma source. In the second step, the experiments were repeated with the Co-60 gamma radioisotope source. The experimental results are given in Table III. Figures $2 \mathrm{a}$ and $2 \mathrm{~b}$ show relative intensity as a function of material thickness for six different aluminum alloys against Cs-137 and Co-60 gamma radioisotope sources, respectively. The graphs of relative intensity as function of material thickness were drawn using the values given in Table III.

TABLE III

\begin{tabular}{|c|c|c|c|c|}
\hline $\begin{array}{c}\text { Aluminum } \\
\text { alloy }\end{array}$ & $\begin{array}{c}\text { Thickness } \\
{[\mathrm{cm}]}\end{array}$ & $\begin{array}{c}\text { Average } \\
\text { count }\end{array}$ & $\begin{array}{l}\text { Standart } \\
\text { deviation }\end{array}$ & $\begin{array}{c}\text { Relative } \\
\text { count }\end{array}$ \\
\hline \multirow{6}{*}{1050} & 0 & 7943 & 282 & 1.000 \\
\hline & 0.0959 & 7862 & 26 & 0.990 \\
\hline & 0.1917 & 7748 & 23 & 0.975 \\
\hline & 0.2872 & 7588 & 62 & 0.955 \\
\hline & 0.3832 & 7315 & 74 & 0.921 \\
\hline & 0.4792 & 7214 & 109 & 0.908 \\
\hline \multirow{6}{*}{3003} & 0 & 8174 & 102 & 1.000 \\
\hline & 0.1949 & 7959 & 133 & 0.974 \\
\hline & 0.3907 & 7689 & 73 & 0.941 \\
\hline & 0.5856 & 7270 & 57 & 0.889 \\
\hline & 0.7800 & 7009 & 86 & 0.857 \\
\hline & 0.9750 & 6658 & 9 & 0.815 \\
\hline \multirow{6}{*}{5005} & 0 & 8075 & 201 & 1.000 \\
\hline & 0.1197 & 8010 & 62 & 0.992 \\
\hline & 0.2382 & 7765 & 56 & 0.962 \\
\hline & 0.3575 & 7537 & 40 & 0.933 \\
\hline & 0.4765 & 7309 & 176 & 0.905 \\
\hline & 0.5958 & 7149 & 135 & 0.885 \\
\hline \multirow{6}{*}{6063} & 0 & 8103 & 62 & 1.000 \\
\hline & 0.2085 & 7832 & 40 & 0.967 \\
\hline & 0.4174 & 7514 & 52 & 0.927 \\
\hline & 0.6289 & 7150 & 3 & 0.882 \\
\hline & 0.8374 & 6824 & 100 & 0.842 \\
\hline & 1.0466 & 6603 & 6 & 0.815 \\
\hline \multirow{6}{*}{7072} & 0 & 7606 & 50 & 1.000 \\
\hline & 0.1949 & 7524 & 70 & 0.989 \\
\hline & 0.3907 & 7073 & 26 & 0.930 \\
\hline & 0.5856 & 6681 & 39 & 0.878 \\
\hline & 0.78 & 6511 & 54 & 0.856 \\
\hline & 0.975 & 6253 & 124 & 0.822 \\
\hline \multirow{6}{*}{8006} & 0 & 7614 & 68 & 1.000 \\
\hline & 0.144 & 7349 & 135 & 0.965 \\
\hline & 0.289 & 7196 & 141 & 0.945 \\
\hline & 0.435 & 6925 & 123 & 0.909 \\
\hline & 0.582 & 6841 & 73 & 0.898 \\
\hline & 0.726 & 6597 & 181 & 0.866 \\
\hline
\end{tabular}

Experimental results for the different aluminum alloys.

The experimental linear attenuation coefficients $(\mu)$ of the materials are shown in Table IV. The experimental mass attenuation coefficients $(\mu / \rho)$ were also calculated for the studied aluminum composites. XCOM computer code was used for calculation of theoretical mass attenuation coefficients [11]. Linear attenuation coefficient, experimental and theoretical mass attenuation coefficients and their difference in percents are given in Table IV. For all samples, the experimental and theoretical mass attenuation coefficients are acceptably close to each other. 

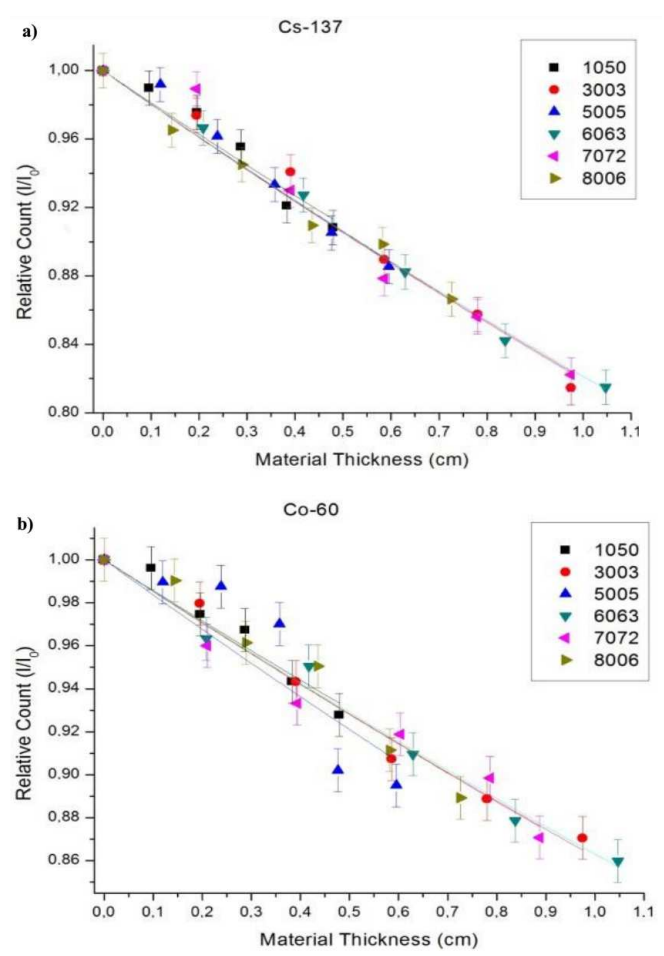

Fig. 2. (a) Attenuation graph for six aluminum alloys against Cs-137. (b) Attenuation graph for six aluminum alloys against Co-60.

\section{Conclusions}

Shielding properties against gamma radiation of six different aluminum alloys were studied. As a result, the increase of the amounts of high-atomic-number elements in the alloy leads to a decrease of the linear and mass attenuation coefficient of studied aluminum alloys. The differences between theoretical and experimental results were in the range of $0.07-10.74 \%$. Therefore the calculated and the experimental results are in agreement with each other.

\section{References}

[1] R. Cobden, A. Banbury, Aluminum Physical Properties, Characteristics and Alloys, Training in Aluminum Technologies, TALAT, EAA, 1994.

[2] W. Hufnagel, Key to Aluminum Alloys, 5th ed., Astm Intl., 1998.

[3] G. Cevikbas, A.B. Tugrul, U. Onen, T. Boyraz, B. Buyuk, AIP Conf. Proc. 1653, 020029 (2015).

[4] B. Buyuk, A.B. Tugrul, Ann. Nucl. Energy 71, 46 (2014).

[5] B. Buyuk, A.B. Tugrul, Radiat. Phys. Chem. 97, 354 (2014).

[6] B. Buyuk, A.B. Tugrul, A.C. Akarsu, A.O. Addemir, Acta Phys. Pol. A 121, 135 (2012).

[7] B. Buyuk, A.B. Tuğrul, S. Aktop, A.O. Addemir, Acta Phys. Pol. A 123, 177 (2013).

[8] B. Buyuk, A.B. Tugrul, A.O. Addemir, N. Ay, Acta Phys. Pol. A 125, 420 (2014).

[9] B. Buyuk, A.B. Tuğrul, Acta Phys. Pol. A 125, 423 (2014).

[10] H. Durmaz, B. Buyuk, A.B. Tuğrul, Acta Phys. Pol. A 125, 469 (2014).

[11] M.J. Berger, J.H. Hubbell, S.M. Seltzer, J. Chang, J.S. Coursey, R. Sukumar, D.S. Zucker, K. Olsen, XCOM: Photon Cross Section Data Base, Www.nist.gov/pml/data/xcom/index.cfm, (accessed 10.3.2015).

TABLE IV

Linear attenuation coefficients and correlation coefficients of the six different aluminum alloys.

\begin{tabular}{|c|c|c|c|c|c|c|c|c|}
\hline \multirow{3}{*}{$\begin{array}{l}\text { Aluminum } \\
\text { alloys }\end{array}$} & \multirow{2}{*}{\multicolumn{2}{|c|}{$\begin{array}{c}\text { Linear } \\
\text { attenuation } \\
\text { Coefficient } \mu \\
{\left[\mathrm{cm}^{-1}\right]}\end{array}$}} & \multicolumn{6}{|c|}{ Mass attenuation coefficient, $\mu / \rho\left[10^{-2} \mathrm{~cm}^{2} / \mathrm{g}\right]$} \\
\hline & & & \multicolumn{3}{|c|}{ Cs-137 } & \multicolumn{3}{|c|}{ Co-60 } \\
\hline & Cs-137 & Co-60 & Experimental & $\begin{array}{l}\text { Theoretical } \\
\text { (XCOM) }\end{array}$ & \begin{tabular}{|c} 
Difference \\
{$[\%]$} \\
\end{tabular} & Experimental & $\begin{array}{c}\text { Theoretical } \\
\text { (XCOM) }\end{array}$ & $\begin{array}{c}\text { Difference } \\
{[\%]}\end{array}$ \\
\hline 1050 & 0.190 & 0.144 & 7.011 & 7.433 & 5.676 & 5.314 & 5.486 & 3.142 \\
\hline 3003 & 0.198 & 0.149 & 7.253 & 7.429 & 2.372 & 5.458 & 5.483 & 0.458 \\
\hline 5005 & 0.198 & 0.164 & 7.333 & 7.432 & 1.328 & 6.074 & 5.485 & 10.740 \\
\hline 6063 & 0.197 & 0.147 & 7.351 & 7.444 & 1.253 & 5.485 & 5.495 & 0.181 \\
\hline 7072 & 0.199 & 0.149 & 7.316 & 7.428 & 1.505 & 5.478 & 5.482 & 0.074 \\
\hline 8006 & 0.198 & 0.149 & 7.226 & 7.426 & 2.690 & 5.438 & 5.480 & 0.767 \\
\hline
\end{tabular}

